\title{
Cloud Trails past Bermuda: A Five-Year Climatology from 2012 to 20160
}

\author{
Michael C. Johnston, Christopher E. Holloway, and Robert S. Plant \\ Department of Meteorology, University of Reading, Reading, United Kingdom
}

(Manuscript received 18 April 2018, in final form 24 September 2018)

\begin{abstract}
Cloud trails are primarily thermally forced bands of cloud that extend downwind of small islands. A novel algorithm to classify conventional geostationary visible-channel satellite images as cloud trail (CT), nontrail (NT), or obscured (OB) is defined. The algorithm is then applied to the warm season months of five years at Bermuda comprising 16400 images. Bermuda's low elevation and location make this island ideal for isolating the role of the island thermal contrast on CT formation. CTs are found to occur at Bermuda with an annual cycle, peaking in July, and a diurnal cycle that peaks in midafternoon. Composites of radiosonde observations and ERA-Interim data suggest that a warm and humid low-level environment is conducive for CT development. From a Lagrangian perspective, wind direction modulates CT formation by maximizing low-level heating on local scales when winds are parallel to the long axis of the island. On larger scales, low-level wind direction also controls low-level humidity through advection.
\end{abstract}

\section{Introduction}

Bermuda is a small, flat island in the western North Atlantic Ocean with a total land area of about $54 \mathrm{~km}^{2}$ and topography not rising more than $76 \mathrm{~m}$ above sea level (CIA 2017). Bermuda is also isolated, more than $1000 \mathrm{~km}$ away from the nearest land in North America to the west and the Caribbean to the south. This situation, somewhat unique to Bermuda, helps to isolate the influence of the island on the impinging flow.

Cloud trails are bands of cloud that extend downwind of small heated islands. This heating results in a thermal perturbation over and downwind of an island in the form of a turbulent plume with associated thermally forced circulations that organize convection into one or more cloud bands. These bands appear anchored to their parent island in animations of visible-channel satellite imagery. Cloud trails are found to occur on "flat" islands such as Nantucket (e.g., Malkus and Bunker 1952; Malkus and Stern 1953); Anegada, British Virgin Islands (Malkus 1963); the Bahamas (Bhumralkar 1973); and Nauru (e.g., Nordeen et al. 2001; McFarlane et al. 2005;

Supplemental information related to this paper is available at the Journals Online website: https://doi.org/10.1175/MWR-D-18-0141.s1.

Corresponding author: Michael C. Johnston, m.c.johnston@ pgr.reading.ac.uk
Matthews et al. 2007). This phenomenon offers a somewhat simplified real-world setting to study the behavior of convection associated with surface heterogeneities.

A similar phenomenon is also observed downwind of heated islands with significant topography: for example, in the Lesser Antilles (peaks near $1500 \mathrm{~m}$ ) (e.g., Garstang et al. 1975; Smith et al. 1997; Kirshbaum and Fairman 2015), the eastern Pacific island of Guadalupe (1300 m) (Dorman 1994), and Hawaii (over $4000 \mathrm{~m}$ ) (e.g., Smolarkiewicz et al. 1988; Yang and Chen 2008; Yang et al. 2008b,a). Such studies suggest that the topography plays a significant role in generating flow perturbations. These perturbations are shown to be of greater magnitude but often with the same sign as the thermal perturbations that result from solar heating (Crook and Tucker 2005; Kirshbaum and Wang 2014). The topography also results in added downstream effects that can interfere with or disrupt cloud trails. Drying because of downstream wave breaking was mentioned by Kirshbaum and Fairman (2015), while vortex shedding could overwhelm any cloud trail signal. These studies highlight the complicating role of topography, and motivate the focus on flat island cases.

In addition to elevation, island size is important in determining the nature of convection that develops in a heated flow. Williams et al. (2004) showed that the island signal in lightning flash rates (a proxy for convective intensity) becomes indistinguishable from the 
background oceanic regime for islands with an area less than $100 \mathrm{~km}^{2}$ (small islands). Similar results were found for the pattern of precipitation over tropical islands by Robinson et al. (2011) and Sobel et al. (2011).

One mechanism for the increase in convective intensity over larger islands is the convergence of sea-breeze fronts (e.g., Crook 2001). However, under no background flow and for a given heating rate, two-dimensional simulations show that the strength of a sea-breeze circulation decreases with island/peninsula size (Savijarvi and Matthews 2004). Savijarvi and Matthews (2004) also found that with some background flow, the windward cell of the weaker sea breezes for smaller islands can be displaced and tilted downwind of the island, transforming the circulation into that of a steady heat island like that in Estoque and Bhumralkar (1969).

Analysis of intensive field campaign observations on Nauru [as part of the Nauru Island Effect Study (NIES); McFarlane et al. (2005)] revealed potential mechanisms for the initiation and maintenance of cloud trails there (Savijarvi and Matthews 2004; Matthews et al. 2007). These authors propose that a thermal internal boundary layer forms and grows as oceanic air advects across the heated island. This turbulent thermal layer then evolves into a warmer, cloud-topped plume downwind of the island. This idea of a warm plume is consistent with the observations at Barbados discussed by Garstang et al. (1975). Matthews et al. (2007) also suggested that the warm plume drives a thermal circulation that may be responsible for the maintenance of the cloud trails that were found to extend on average $125 \mathrm{~km}$ downwind of Nauru (Nordeen et al. 2001).

Cloud trail climatologies at Nauru and in the Lesser Antilles were made using visible-channel satellite imagery (Nordeen et al. 2001; Kirshbaum and Fairman 2015). Each hourly image was manually classified by Nordeen et al. (2001) as either "cloud plume"-a line of cloud is seen extending downwind of and anchored to the island; "nonplume"- there is no evident band of anchored cloud; or "obscured"- the island is obscured from view by larger-scale cloud phenomena. The current study will follow this definition, but referring to cloud trail (CT), nontrail (NT), and obscured (OB) scenes, respectively.

Both Nordeen et al. (2001) and Kirshbaum and Fairman (2015) showed that strong surface heating during the day was important for CT development. CT occurrence was seen to peak in midafternoon both at Nauru and the Lesser Antilles. At Nauru, this diurnal cycle in CT occurrence combined with the low elevation of Nauru (only rising to $30 \mathrm{~m}$ above sea level) reinforces the idea that cloud trails are primarily thermally driven by the difference in low-level heating between the island and surrounding ocean (Nordeen et al. 2001).
In the following sections, a simple automated method for classifying visible-channel satellite imagery at Bermuda as cloud trail, nontrail, or obscured is outlined. The choice of an automated classification scheme has the benefits of reproducibility, objectivity, and expedience over manual classifications. Further, it has the potential to be quickly adapted for other locations or similar problems.

This is applied to 16400 images over five years to construct a climatology. We then use these classifications in conjunction with radiosonde observations and ECMWF interim reanalysis (ERA-Interim) data to describe the environments that coincide with each classification. Finally, we discuss some cloud trail behavior at Bermuda and why some environments appear more favorable for CT formation.

\section{Methods}

\section{a. Data}

Imagery from the visible $(0.64 \mu \mathrm{m})$ channel of the Geostationary Operational Environmental Satellite-13 (GOES-13) is used to identify CT and thereby construct a climatology of their occurrence. GOES-13 is operated by the U.S. National Oceanic and Atmospheric Administration (NOAA) and National Aeronautics and Space Administration (NASA). Data with a nominal resolution of $1 \mathrm{~km}$ and $30 \mathrm{~min}$ used in this study are accessed through the Comprehensive Large Array-Data Stewardship System (CLASS) archives at NOAA's National Climatic Data Center (NCDC) (NOAA/Office of Satellite and Product Operations and NOAA/Center for Satellite Applications and Research 1994).

Radiosonde observations taken at Bermuda, near $32.3^{\circ} \mathrm{N}, 64.8^{\circ} \mathrm{W}$, are sourced from the Integrated Global Radiosonde Archive, version 2 (IGRAv2). This dataset replaces the previous version of IGRA (e.g., Durre et al. 2006, 2008). At Bermuda, radiosondes are regularly launched once per day at 0900 LT (1200 UTC). In this study, to compare radiosondes on different days, the temperature, pressure, and relative humidity measurements are linearly interpolated to regularly spaced pressure levels from 1000 to $100 \mathrm{hPa}$ with 5 -hPa increments. After interpolation, the potential temperature is calculated as follows:

$$
\theta=T\left(\frac{p_{0}}{p}\right)^{R_{d} / c_{p}},
$$

where $\theta$ is the potential temperature in kelvins, $T$ is the temperature in kelvins, $p_{0}$ is a reference pressure set to $1000 \mathrm{hPa}, p$ is the pressure in $\mathrm{hPa}, R_{d}$ is the gas constant for dry air taken to be $287 \mathrm{~J} \mathrm{~kg}^{-1} \mathrm{~K}^{-1}$, and $c_{p}$ is the 
specific heat capacity of dry air at constant pressure, taken to be $1004 \mathrm{~J} \mathrm{~kg}^{-1} \mathrm{~K}^{-1}$.

Surface data at Bermuda are provided by the Bermuda Weather Service. Wind speed and direction measurements used in this study are 10-min averages measured at $10 \mathrm{~m}$ above ground level with observations every $10 \mathrm{~min}$. These measurements are taken at Bermuda's L. F. Wade International Airport, on runway 12 (at the northwest end of the airfield). Air temperature and relative humidity at $1.5 \mathrm{~m}$ are also provided by the Bermuda Weather Service in hourly observations.

Finally, ERA-Interim data (Dee et al.2011) are used to investigate the large-scale environment. Temperature, specific humidity, three-dimensional wind components, and mean sea level pressure are used.

The period of interest for this study is May-October in the years 2012-16. May-October is referred to as the "warm season" in this study. At Bermuda's latitude, there is a stronger annual cycle in the large-scale environment than at Nauru or in the Caribbean Sea. Further, the solar zenith angle is higher and therefore the diurnal surface heating is weaker during the remaining months (November-April, or the "cool season").

Reanalysis data show that the North Atlantic subtropical high (Bermuda-Azores high) is most intense and extensive during the warm season-peaking in July. The cool season marks the period where the Bermuda-Azores high is less influential or absent and so midlatitude cyclones and their fronts play a larger role in the local weather. It maintains largely settled weather across the western Atlantic. This is consistent with findings by Davis et al. (1997) on the variability of the North Atlantic anticyclone. Given that large-scale disturbances can both obscure the island in cloud and disrupt cloud trail formation with precipitation and sudden wind shifts, only the warm season is considered for its more settled regime.

\section{b. Manual classification method}

Initially, a manual classification of the first warm season (May-October 2012) is performed to both aid in the design of an automated method for classification, and validate the automated classifications. Scenes are classified using the three categories (CT, NT, and $\mathrm{OB}$ ) outlined above. Here, a scene refers to a visible-channel satellite image cropped to a $4^{\circ} \times 4^{\circ}$ domain centered on Bermuda. The surface wind direction is used to determine where the downwind side of the island is in each scene.

Scenes are classified as CT if the area around the island is not covered in cloud and a band or bands of cloud are seen downwind of and apparently anchored to Bermuda (e.g., Fig. 1a). If the area around the island is not covered in cloud, but no band of cloud is seen anchored downwind of the island, the scene is classified as
NT (e.g., Fig. 1b). Finally, if the scene is mostly cloudy, particularly in such a way that covers much of the island from view, it is classified as OB (e.g., Fig. 1c).

While this exercise is somewhat subjective, the majority of scenes were straightforward to classify. The biggest challenge was in distinguishing between downwind cloud bands that are CT against those that are associated with other phenomena such as low-level convergence not linked to the island, cold pools, etc. It is suspected that these features may be misclassified by an intentionally simplistic automated approach.

See supplemental material for a table of the dates and times of manually classified visible-channel imagery, and the corresponding manual classification.

\section{c. Algorithm for automated classification}

From our manual classification and the previous work discussed above, we know that (i) CT are either absent or hidden from view by other large-scale cloud in OB scenes, and (ii) $\mathrm{CT}$ are characterized by more cloud downwind of the island than upwind. These two ideas are used to design an algorithm to automate the classification of scenes into our three categories.

First, cloudy and cloud-free pixels must be identified. Each pixel is nominally $1 \mathrm{~km} \times 1 \mathrm{~km}$. The albedo from the visible-channel satellite data is used to identify cloudy pixels. For simplicity we create a binary cloud mask based on an albedo threshold. Pixels are called "cloudy" and given a value of " 1 " if the albedo is greater than the albedo threshold. Remaining pixels with albedo less than this threshold are given a value of " 0 ." Figure 2 shows an example of a visible-channel satellite image in (Fig. 2a) and the cloud mask that results from this method in (Fig. 2b).

Sensitivity tests (not shown) on the choice of albedo threshold for a mostly cloud-free day with a cloud trail in the afternoon hours [according to observations from the L. F. Wade International Airport (TXKF) and the manual classification] indicate that if the albedo threshold is lower than 0.10, the land area of Bermuda and the shallow water surrounding Bermuda is falsely masked as cloud (e.g., Fig. 1b). Conversely, if the threshold is greater than 0.20 , pixels containing smaller cloud elements, or pixels that are part of regions of thin cloud might be falsely masked as not cloudy. The albedo threshold is taken to be 0.15 , as a compromise between these two limits and the same value used in Yang and Chen (2008) and Kirshbaum and Fairman (2015).

A known issue with this simple masking method is that cloud cover over land and coastal regions remains somewhat ambiguous. Land provides a higher background albedo than the ocean. Land pixels may therefore still erroneously be masked as cloudy. Pixels over land, and one pixel away from the coastline are therefore excluded from calculations to account for this issue. 

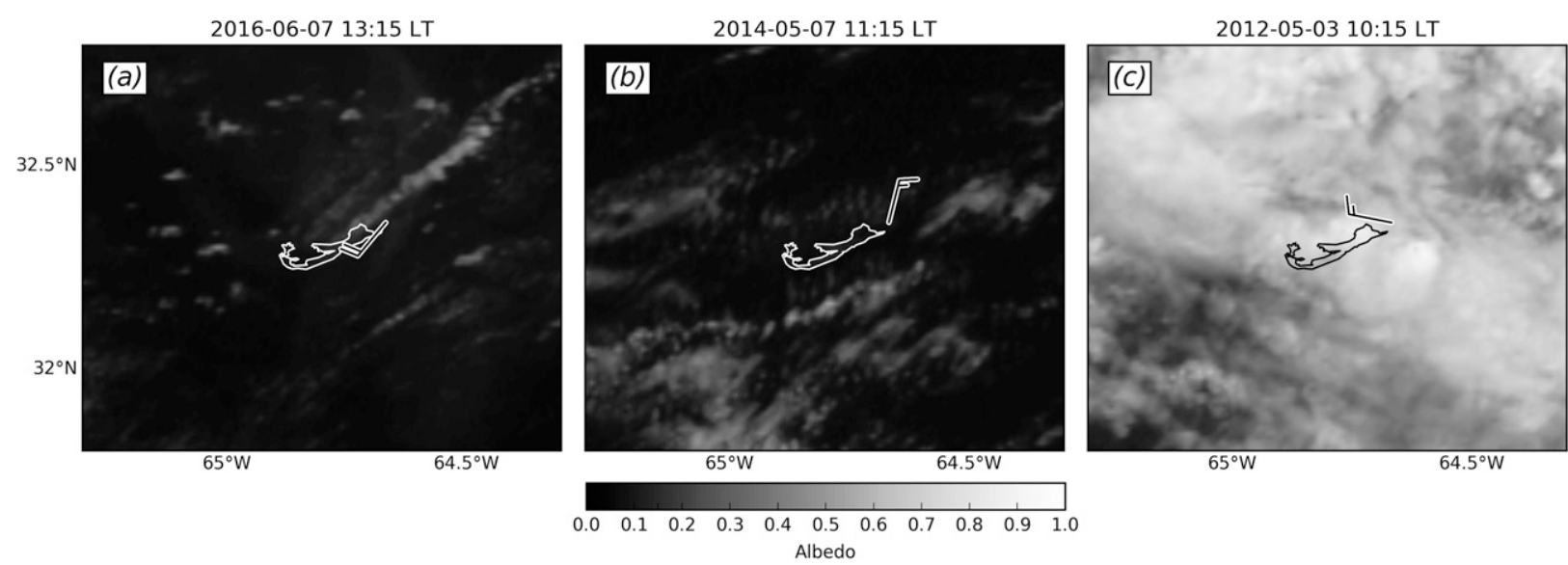

FIG. 1. GOES-13 visible-channel satellite imagery showing example scenes. (a) CT scene where clouds organize into a band downwind of Bermuda as indicated by a southwest-northeast-oriented band of higher albedo. (b) NT scene in which there are few clouds and some of the higher albedo near and over the island might be shallow water and land showing up rather than cloud. (c) OB scene where the island (and much of the surroundings) is obscured from view by widespread cloud as indicated by high albedo throughout the scene. In each example, a wind barb is plotted showing 10-m wind direction and speed in knots at TXKF provided by the Bermuda Weather Service.

Furthermore, for high solar zenith angles, spurious regions of high or low albedo can appear depending on the cloud cover. For instance, individual towering clouds might cast shadows on other cloudy regions - these shadowed areas are then falsely masked as cloud free. Similarly, at sunrise and sunset (when the solar zenith angle is $90^{\circ}$ ) there can be a very bright line through the scene. Scenes must then be rejected if the maximum solar zenith angle is too high. To accomplish this, five sample scenes that were obviously impacted by the abovementioned effects were chosen. All scenes with solar zenith angle less than some threshold are then discarded. This threshold is determined by taking a first guess of $90^{\circ}$ and decreasing the threshold by $5^{\circ}$ increments until the five sample scenes are discounted. We find that scenes with a solar zenith angle $<75^{\circ}$ are sufficiently illuminated to avoid these high solar zenith angle issues.

Once a scene is subjected to this solar zenith angle test and converted to a cloud mask, it is then assessed for the presence of a CT. In the algorithm, a scene is first classified as $\mathrm{OB}$, or non-OB (i.e., including both the $\mathrm{CT}$ and NT classifications). Then, the non-OB scenes are further subdivided into CT or NT categories.

A circular region of interest with radius $0.25^{\circ}$ (about $25 \mathrm{~km}$ ) centered on Bermuda is considered. This circle contains the entire island and the edges of this circle are at least $0.10^{\circ}(10 \mathrm{~km})$ away from any land points (Fig. 2c). To determine how cloudy the scene is and, therefore, whether or not to classify it as OB, the cloud fraction in that circular area is calculated. Here, the cloud fraction is defined as the spatial mean of the cloud mask over a given area. Scenes with a cloud fraction in the circular region greater than a threshold $\alpha$ are classified as OB. If the cloud fraction is less than $\alpha$, then the scene is non-OB and tested further.
The non-OB scenes are further sorted into NT and CT classifications. As seen in loops of visible-channel satellite imagery and reported in the literature above, CT initiate at the island and extend downwind, forming a band of cloud anchored to the island. Nordeen et al. (2001) used cloud level (the mean over the 950-850-hPa layer) wind directions from once-daily radiosondes to manually identify CT at Nauru. However, while it may be reasonable to assume that there is no significant change in wind direction during the day at Nauru because it is well embedded in the tropical Pacific trade wind region, Bermuda is near the axis of the BermudaAzores high and small changes in the position of this ridge axis could mean a reversal in the wind direction.

McFarlane et al. (2005) showed that at Nauru, the surface wind direction compares well with the heading of identified CT. We have found that the 0900 LT pressureweighted cloud level (950-850-hPa mean) wind direction from radiosonde ascents at Bermuda compare well with the surface winds measured at the same time at Bermuda (not shown). For the purposes of this study, it therefore appears reasonable to use the half-hourly surface wind direction from TXKF to determine where upwind and downwind directions are relative to Bermuda.

The same circular $0.25^{\circ}$ area used to test for OB scenes is now divided into $10^{\circ}$ sectors, 36 in all (Fig. 2d). The first sector is centered on the north. We expect the CT signal to be strongest nearer to the island because of the anchoring described above. From sensitivity tests, if the radius of the circle is too large, the sectors start to become broader than the $\mathrm{CT}$ and so the signal in sector cloud fraction becomes damped (not shown). At distances of $0.25^{\circ}$, a sector is roughly $4.4 \mathrm{~km}$ wide. 


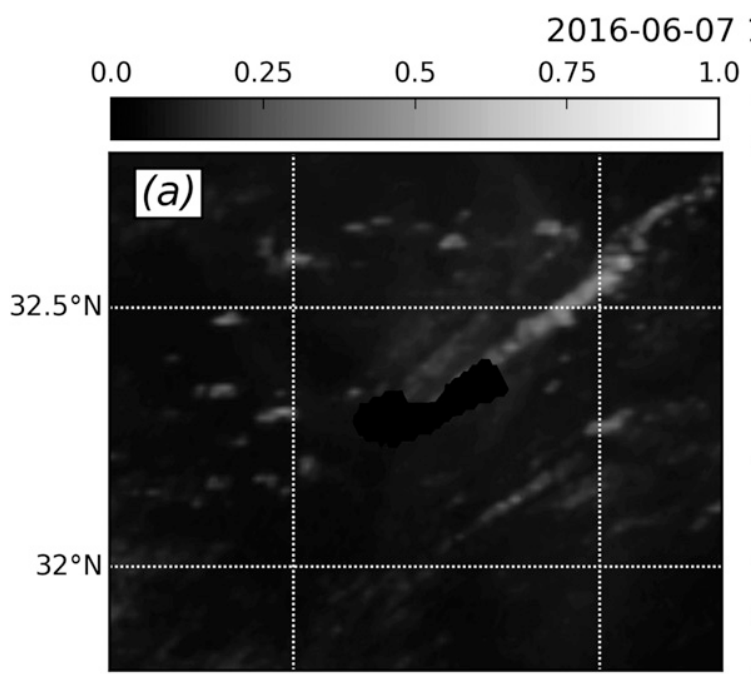

1.0

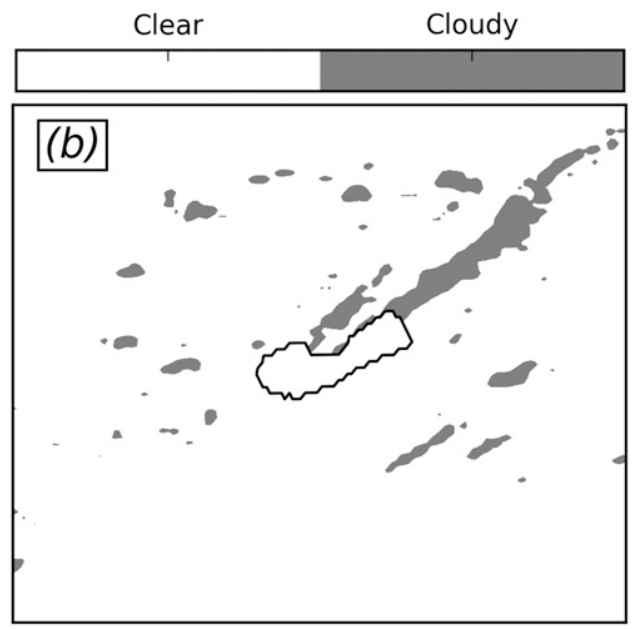

Clear

Cloudy
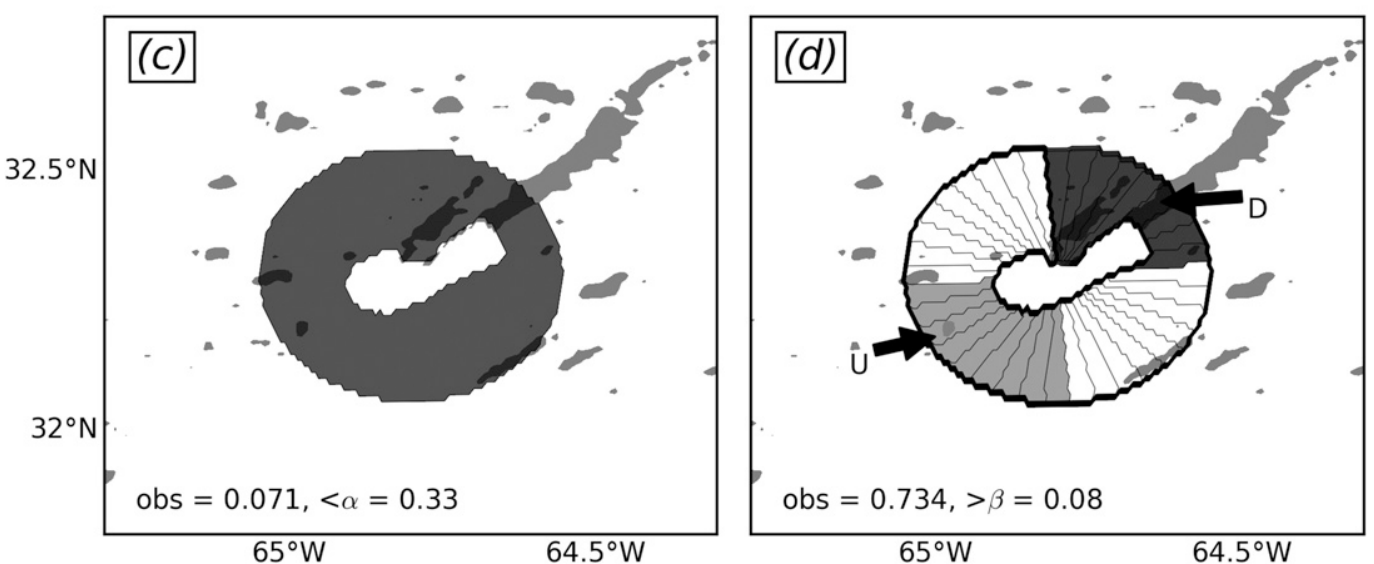

FIG. 2. A walk through of the steps taken to classify each scene. (a) GOES-13 visible-channel satellite imagery. (b) Cloud mask applied to (a), cloudy pixels are shown in gray. (c) The cloud fraction in the circular area centered on $32.3^{\circ} \mathrm{N}, 64.8^{\circ} \mathrm{W}$ with a radius of $0.25^{\circ}$ (dark gray shaded region) is used to determine if the scene is OB. In this example, the cloud fraction is 0.071 , which is less than $\alpha=0.33$ and so the scene is non-OB. (d) Since the scene is non-OB, the same circular area from (c) is split into $10^{\circ}$ wide sectors, 36 in total. The $10-\mathrm{m}$ wind direction at TXKF is used to find the upwind and downwind quadrant (i.e., nine sectors in each direction). The cloud fraction is calculated for each sector of the upwind quadrant (light gray) and the downwind quadrant (dark gray). The difference between the maximum downwind cloud fraction (arrow marked with "D") and the maximum upwind cloud fraction (arrow marked "U") has to be greater than $\beta=0.08$ for the scene to be classified as CT.

As a result of Bermuda's geometry, some sectors contain more nonland pixels than others. Sensitivity to the number of pixels used for cloud fraction computations was tested by using sectors of different lengths and shapes to make them contain more similar number of pixels. The results are found to be generally insensitive to having a more equal pixel count in each sector.

Half-hourly $10-\mathrm{m}$ wind direction observations are used to locate the upwind and downwind sectors. To account for fluctuations in the wind direction, differences between wind direction and CT heading, and CT occurring across two sectors, nine sectors centered on the wind direction are considered. Next, the cloud fraction is calculated for each of nine sectors and the maximum cloud fraction of those sectors is taken to represent the upwind or downwind cloud fraction (marked as "U" and "D," respectively, in Fig. 2d).

The difference between the downwind and upwind sector maximum cloud fractions $(\delta F)$ is taken. Since CT are characterized by organized cloudiness downwind of islands, it follows that there should be a higher downwind cloud fraction than upwind cloud fraction. The term $\delta F$ must be $>0$ to satisfy this condition. However, we also wish to exclude small differences that may be due to random sampling of an undisturbed cloud field. Hence, $\delta F$ must be compared to a threshold $(\beta)$ based on cloud fraction statistics for the chosen definition of upwind and downwind sectors. 
Values chosen in our algorithm for $\alpha$ and $\beta$ are discussed in section $2 \mathrm{~d}$.

\section{d. Algorithm parameters}

Assuming the manual classification is the "truth," it is used to estimate optimal values for $\alpha$ (the cloud fraction threshold above which a scene is classified as OB) and $\beta$ (the $\delta F$ difference threshold above which a scene is classified as CT). For $\alpha$, the cloud fraction is computed for each manually classified scene as described in the above section for discriminating between $\mathrm{OB}$ and nonOB scenes. We then consider the cumulative distribution of this cloud fraction for the OB scenes, and the inverse cumulative distribution for the non-OB scenes. The cloud fraction at which these two distributions intersect is taken to be the optimal value for $\alpha$. With our manual classifications, we find $\alpha$ to be 0.33 .

To determine the value of $\beta$ we again refer to the manual classification. We apply our above method for discriminating between NT and CT scenes to all non-OB scenes. We then consider the cumulative distribution of $\delta F$ for CT scenes, and the inverse cumulative distribution of $\delta F$ for the NT scenes. Again, the $\delta F$ where these two distributions intersect, 0.08 , is taken as the value for $\beta$. For more information on this process, please refer to the appendix.

Sensitivity tests (not shown) suggest that the overall patterns of the annual and diurnal cycle are not very sensitive to the choice of $\alpha$ and $\beta$. We remark that $\alpha=0.33$ is of a similar magnitude to the mean cloud fraction for all days across the period of interest (0.342). A more conservative (higher) value for $\beta$ yields a more confident CT classification at the expense of rejecting the cases with more complex background cloud.

\section{Results and discussion}

\section{a. Algorithm validation}

In effect, by our definitions for $\alpha$ and $\beta$, we are maximizing the Peirce skill score (PSS). This score ranges from -1 to 1 where 1 indicates a perfect classification, and 0 indicates no skill in classifying scenes. Peirce (1884) defines it as follows:

$$
\mathrm{PSS}=\left(\frac{H}{H+M}\right)-\left(\frac{F}{F+C}\right),
$$

where PSS is the Peirce skill score, $H$ is the number of hits, $M$ is the number of misses, $F$ is the number of false alarms, and $C$ is the number of correct negatives. This score describes the match when there are two possible outcomes, $a$ (event occurs) or $b$ (event does not occur).
The corresponding algorithm-manual pairs are $a a$ for hit, $b a$ for miss, $a b$ for false alarm, and $b b$ for correct negative. For $\alpha, a$ refers to an OB classification, and $b$ refers to non-OB classification. At this stage the algorithm has only made $\mathrm{OB}$ and non-OB classifications, the manual NT and CT classifications both count toward non-OB. For $\beta$, we ask what classification would the algorithm assign to the scenes that are manually classified as non-OB. In this case, $a$ refers to a CT classification and $b$ refers to an NT classification.

The PSS can then be applied to the individual categories. Following the $a$ and $b$ framework above for CT classifications, $a$ refers to a CT classification, and $b$ refers to either NT or OB classification. In these cases a correct negative $(b b)$ can be any combination of the two nonevent scenes (e.g., NT-NT, NT-OB, OB-NT, or OB-OB).

For CT, the PSS is 0.51 . It is 0.46 for NT classifications, and 0.82 for OB classifications. Overall, the algorithm has a score of 0.60 . The reader must be reminded that the manual classification process is subjective, so while we take it to be the truth in determining our algorithm parameters in the previous section, and for validation purposes here, it should be understood that it is subject to human error and interpretation differences. Despite this, the manual classification is still instructive for building intuition for what to expect from the algorithm classifications.

However, the PSS does not describe every aspect of algorithm performance. Contingency tables have been produced to further aid in quantifying the algorithm's performance. Shown in Table 1 (left) are the contingency table results for the CT classification. Included in the table are the number of "hits," "misses," "false alarms," and "correct negatives" as described above. The same four categories are shown for NT and OB classifications in Table 1 (middle and right).

In all cases, there are more hits than either false alarms or misses. Commonly used metrics derived from such contingency tables are the "hit rate" and "false alarm rate" given by

$$
\begin{aligned}
\mathrm{HR} & =100 \times \frac{H}{H+M}, \\
\mathrm{FAR} & =100 \times \frac{F}{F+C},
\end{aligned}
$$

respectively, and $H, M, F$, and $C$ are as explained above. Compared to the manual classification of the 2012 warm season, we find that the hit rate [Eq. (3a)] is much higher than the false alarm rate [Eq. (3b)] for each classification. These are $67.0 \%$ versus $15.6 \%$ for CT, $59.5 \%$ versus $13.1 \%$ for NT, and $91.0 \%$ versus $9.1 \%$ for $\mathrm{OB}$. 
TABLE 1. Contingency tables for CT classifications, NT classifications, and OB classifications. Using the CT classification as an example: top left are "hits" where the algorithm and the manual classifications are both CT; top right are "false alarms" where the algorithm classification is CT, but the manual classification is not CT; bottom right are "correct negatives" where the algorithm and the manual classifications are both not CT; and bottom left are "misses" where the algorithm classification is not CT, but the manual classification is CT.

\begin{tabular}{|c|c|c|c|c|c|c|c|}
\hline \multicolumn{2}{|r|}{ Class } & \multicolumn{2}{|c|}{ CT } & \multicolumn{2}{|c|}{ NT } & \multicolumn{2}{|c|}{ OB } \\
\hline Hits & False alarms & 649 & 371 & 743 & 275 & 1117 & 193 \\
\hline Misses & Correct negatives & 320 & 2008 & 506 & 1824 & 111 & 1927 \\
\hline
\end{tabular}

Finally, we consider the bias score for each of our algorithm classifications. The bias score is defined as follows:

$$
\text { BIAS }=\frac{H+F}{H+M}
$$

This quantity can range from 0 to $\infty$, where a score of 1 represents a perfect classification, values less than 1 indicates the algorithm is biased against making a classification, and values greater than 1 indicate that the algorithm is biased toward making a given classification. Using the data provided in Table 1 we find the bias to be 1.05 for cloud trail classifications, 0.82 for nontrail classifications, 1.07 for obscured classifications, and 0.97 overall.

Taken all together, these scores suggest that the algorithm is skillful in making classifications as compared to our subjective manual classification. Furthermore, it is not strongly biased toward or against making any particular classification. We therefore apply the algorithm to subsequent data to extend our analysis period to include May-October of 2012-16.

We have repeated much of the following analysis for the manual classifications and the algorithm classifications for 2012 only to provide further confidence in our conclusions. See the appendix for details.

\section{b. Cloud trail climatology}

We have shown that for May-October of 2012, the algorithm compares well with the manual classification. We can therefore confidently apply the algorithm to automate the classification of longer periods of satellite imagery and explore a longer climatology than previously investigated in literature. From this climatology, it will then be possible to study the environmental differences between days predominately in each classification.

The algorithm is used to classify visible-channel satellite imagery for May-October of 2012-16. These classifications are then sorted by time of day and by month. This aids in exploring the annual and diurnal

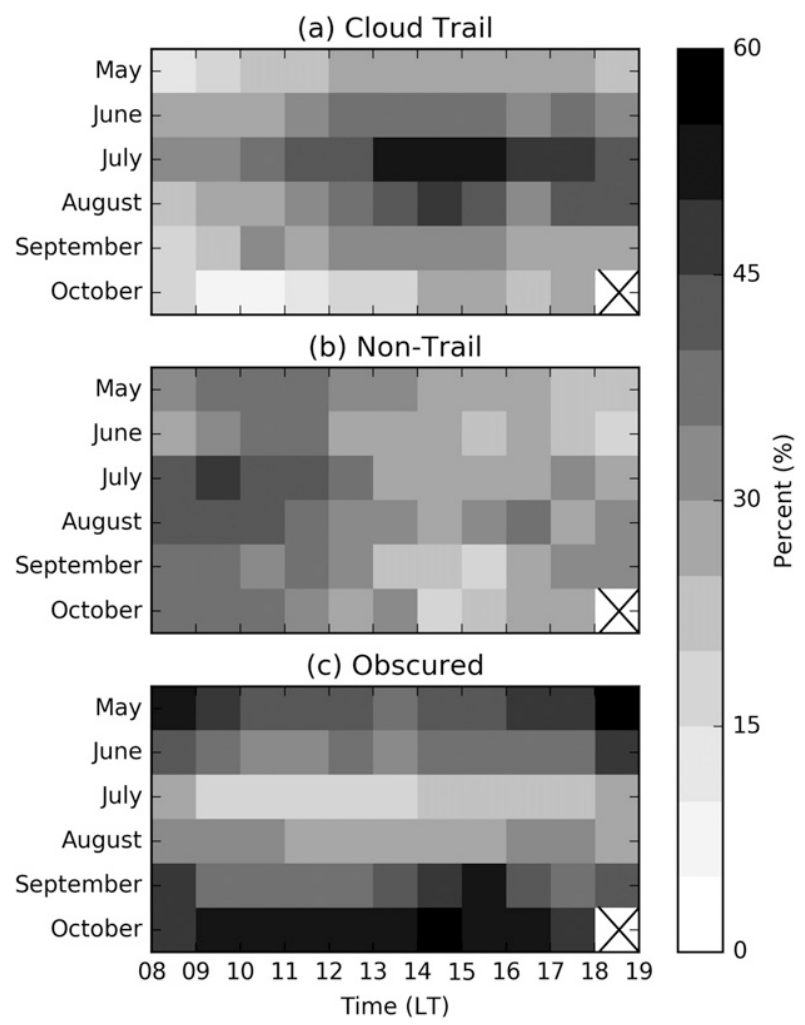

FIG. 3. The fraction of total scenes in each classification arranged by local time and month for the (a) CT, (b) NT, and (c) OB categories. For example the top left cell of (a) represents the percent of all scenes in May between 0800 and 0900 LT that are classified as CT. The three panels sum to $100 \%$. The diurnal cycle progresses from (left) morning to (right) evening, and the annual cycle progresses from (top) May to (bottom) October in each panel. The cells with an " $X$ " in them represent times when all images are rejected because of high solar zenith angles.

cycles (Fig. 3). As part of the annual cycle, the percentage of $\mathrm{OB}$ scenes decreases to a local minimum in July-the same month in which the percentage of CT scenes increases to a maximum. For all times of day, the percentage of CT scenes nearly doubles from $24 \%$ in May to $44 \%$ in July, while OB scenes decrease from $45 \%$ to $22 \%$. Meanwhile, the percentage of NT scenes is steadier at between $29 \%$ and $35 \%$ (on the higher end in July and August).

Similarly, a diurnal cycle is evident when considering rows in Fig. 3. The morning is characterized by a higher percentage of NT than CT scenes, and this reverses in the afternoon and evening. As a seasonal average, the percentage of NT scenes declines from near $38 \%$ in the morning to near $28 \%$ in the afternoon. Concurrently, CT scenes increase from near $24 \%$ in the morning, to near $36 \%$ in the afternoon-offsetting the majority of the change in NT percentage. The percentage of OB scenes varies less through the day; between $40 \%$ in the 
early morning and late evening, and $34 \%$ around 1100 LT. This local minimum in OB scenes occurs around the same time as the decrease in the percentage of NT scenes and the increase in the percentage of CT scenes.

For days with CT scenes, the median first such scene is identified at 0945 LT and median final scene at 1745 LT. The first CT scenes are identified earliest in the day in June and the last scene is latest in the day in August. The first CT scene occurs later and the last occurs earlier in May and October. In this part of the analysis, only days with two or more consecutive CT scenes are considered. Cases in which CT occurred outside of the range of times with sufficiently low solar zenith angles are expected, and such scenes cannot be classified by the algorithm. This would result in a real start time that is earlier than detected in the algorithm. However, there is a counteracting tendency for the algorithm to make more early morning CT classifications than what was manually classified (see the appendix).

More than one period of consecutive CT scenes may be classified on a given day. This is seen in both the manual classification of just May-October 2012, and the algorithm classification for the same period. Comparing the manual classification to just the algorithm classification for months in 2012 , we see that $59 \%$ of days have just one period in the manual classification, and up to three periods occur per day. However, in the algorithm classification for 2012, only $23 \%$ of days have one continuous period of CT scenes (an additional $31 \%$ have two periods, and there were four days on which six periods were identified by the algorithm). Physically, we can explain more than one CT period as occurring when the environment is marginal for $\mathrm{CT}$ formation. Changes in the wind direction might then alter the strength of the island thermally driven lift by no longer paralleling the long axis of the island, or a decrease in low-level humidity might make cloud formation unobtainable by lift of the same strength. Either change, or some combination of both might cause the CT to temporarily dissipate before conditions return to allow the CT to redevelop. However, these may also be explained as artifacts of the algorithm. If the large scale cloudiness is near the threshold for distinguishing between $\mathrm{OB}$ and non-OB scenes $(\alpha)$ a small increase in cloud cover might fool the algorithm into classifying real $\mathrm{CT}$ as $\mathrm{OB}$ scenes. Similarly, if there is an increase in the ambient upwind cloud (e.g., due to an advancing front), the algorithm might be fooled into making an NT classification as the downwind-upwind cloud fraction difference is no longer greater than our threshold $\beta$.

This climatology reveals that during the period of peak CT occurrence in July, there is also a peak in their duration. The mean duration increases from $1 \mathrm{~h} 58 \mathrm{~min}$ in May to a peak of $3 \mathrm{~h} 17 \mathrm{~min}$ in July before decreasing to $1 \mathrm{~h} 34 \mathrm{~min}$ in October when our period of study ends (not shown). CT that persist for just one scene are taken to have a duration of half an hour here, and those that persist for two or more consecutive scenes are considered to have one hour duration. Each additional consecutive scene is counted as a further half hour of duration. On days in which more than one period occurs, the longest duration is taken as the value for that day. Comparing the manual and algorithm classifications for just 2012, we find that the manually classified CT last roughly twice as long because of the increased intermittency in the algorithm classification.

For scenes that were manually classified as having CT (May-October of 2012), we manually estimated the length of the CT in that scene by finding its end-point in the visible-channel satellite imagery and calculating the distance between that point and the center-point of the island (assuming that this is where the CT originated). This follows the methodology outlined by Nordeen et al. (2001).

We then consider the half-hourly mean CT length estimated for the manually classified imagery. First, there is a local maximum in CT length $(78 \mathrm{~km})$ at 0815 LT, and this then decreases to a local minimum $(41 \mathrm{~km})$ by 0915 LT (not shown). This early morning CT is consistent with the discussion above on the one or more short-lived CT.

Our second observation is that the CT length tends to increase through the remainder of the day. The CT on average grow from the local minimum length at 0915 LT, until $1515 \mathrm{LT}$ when they are about $90 \mathrm{~km}$ in length. The mean length remains near 90-95 km through sunset. Using the 10-m wind speed and the estimated length, we predict the length half an hour later (the time of the next scene) assuming advection is the only factor controlling changes in length. We find these predictions to be in generally good agreement with the manually estimated lengths with a correlation coefficient of $0.75\left(R^{2}=0.55\right)$ on 109 length predictions (not shown). Additional factors, such as precipitation or evaporation of cloud liquid due to entrainment of drier surrounding air might act against the increase due to advection.

\section{c. Environmental characteristics}

One goal of this study is to describe and highlight differences between CT-, NT-, and OB-dominated environments. To do this, we composite radiosonde data and ERA-Interim reanalysis data by classification. As there is an annual cycle at Bermuda in both the classifications and the environmental conditions, we only consider the peak of the CT season June-August (JJA) to avoid reproducing the signal of the annual cycle in our composites. 
Most days are not completely in one single classification. However, the radiosonde data are available once per day at $0900 \mathrm{LT}$. This presents the challenge of assigning a single classification to a day made of several classifications.

To do this, the fraction of each day in each classification is calculated for all days in the period MayOctober 2012-16. Next, we evaluate the 75th percentile of these fractions for each classification. If the fraction of a given day in a given classification is greater than its 75th percentile, that day is assigned to that classification and included in that classification's composite.

For example, the 75th percentile for the fraction of day classified as CT is found to be $59 \%$. If at least $59 \%$ of the day's classified scenes are CT, then the data for that day are included in the CT composite. The 75th percentiles for NT and OB are 50\% and 59\% respectively. The same day cannot be assigned to more than one classification by this method since any two of the three 75th percentile thresholds will always sum to greater than $100 \%$.

The interpolated IGRAv2 data are used to consider the anomalies from the 0900 LT JJA 2012-16 mean potential temperature and relative humidity profiles. Radiosonde ascents that are incomplete below $700 \mathrm{hPa}$ are not included in the composites. The resulting radiosonde composites for each classification are shown in Fig. 4. The mean profile of potential temperature and composite anomalies (Figs. 4a,b) and the mean profile of relative humidity and composite anomalies (Figs. 4c,d) are shown for the layer between the surface and $700 \mathrm{hPa}$. With this method, about $25 \%$ of the JJA days are assigned to each classification's composite-leaving about $25 \%$ of the days to be discarded.

For each composite, we assume that the mean anomaly is the center of a normal distribution of anomaly profiles. We then estimate this uncertainty as the standard error: $\sigma / \sqrt{N}$, where $N$ is the number of observations in a given composite.

The CT-dominated days (dark gray dash-dot profiles in Fig. 4) have the highest surface potential temperature of the three classifications. Potential temperature anomalies (Fig. 4b) decrease in magnitude to near zero above $950 \mathrm{hPa}$, indicating a less stable than normal boundary layer. The anomalies then increase to become positive again by $700 \mathrm{hPa}$, indicating that the layer aloft is slightly more stable than climatology for this period. These conditions have long been regarded as favorable for shallow convection (e.g., Malkus 1952).

The composite profile of potential temperature anomalies for NT-dominated days (medium gray dashed profiles in Fig. 4) has a similar shape to that for the CTdominated days indicating a similar pattern of stability anomalies. However, the NT anomalies are smaller than the CT anomalies throughout the entire lower troposphere shown, and feature potential temperatures below normal between 1000 and $850 \mathrm{hPa}$ (Fig. 4b).

A very different potential temperature regime occurs for the OB-dominated days (the light gray, dotted profiles in Fig. 4). The lowest $100 \mathrm{hPa}$ is more stable than normal, while the profile is less stable than normal aloft. This pattern is consistent with the idea that the OB days are associated with large-scale cloudiness. Lower than normal near-surface potential temperatures are an expected consequence of cloud shading and possible evaporative cooling from precipitation.

Similarly, a clear separation between the classifications is evident in the relative humidity anomaly composites (Fig. 4d). The OB-dominated days have the highest surface relative humidity, but the OB- and CT-dominated days have similar, near-normal relative humidity between 1000 and $950 \mathrm{hPa}$. Above $950 \mathrm{hPa}$, the CT profile remains near normal, becoming slightly drier than normal while the OB profile becomes much more humid than normal. The NT profile again has a similar shape to the CT profile, but is drier than normal throughout this layer.

Overall, CT-dominated days are warmer than normal below $700 \mathrm{hPa}$ with near-normal relative humidity, while NT-dominated days are cooler and drier than normal below $700 \mathrm{hPa}$. The higher low-level relative humidity on CT-dominated days implies a lower lifting condensation level (LCL) than for NT-dominated days. However, the warmer low levels on CT-dominated days imply a higher LCL than for the NT case. We therefore calculate the height of the LCL to further examine this relationship. We use Bolton (1980)'s formula for the temperature of the LCL:

$$
T_{\mathrm{LCL}}=\frac{1}{\frac{1}{T_{D}-56}+\frac{\ln \left(T_{K} / T_{D}\right)}{800}}+56,
$$

where $T_{D}$ is the surface dewpoint temperature and $T_{K}$ is the surface temperature (both temperatures are in kelvin). This can then be used to find the pressure of the LCL as follows:

$$
p_{\mathrm{LCL}}=p_{s}\left(\frac{T_{\mathrm{LCL}}}{T_{K}}\right)^{c_{p} / R_{d}},
$$

where $p_{\mathrm{LCL}}$ is the pressure of the LCL, $p_{s}$ is the surface pressure, and $c_{p}$ and $R_{d}$ are as defined in the previous section.

The composite LCL pressure for each classification and the climatology are marked in Fig. 4c. We find that the mean composite LCL pressure for CT-dominated days is $955 \mathrm{hPa}$. This corresponds to a lower height than 

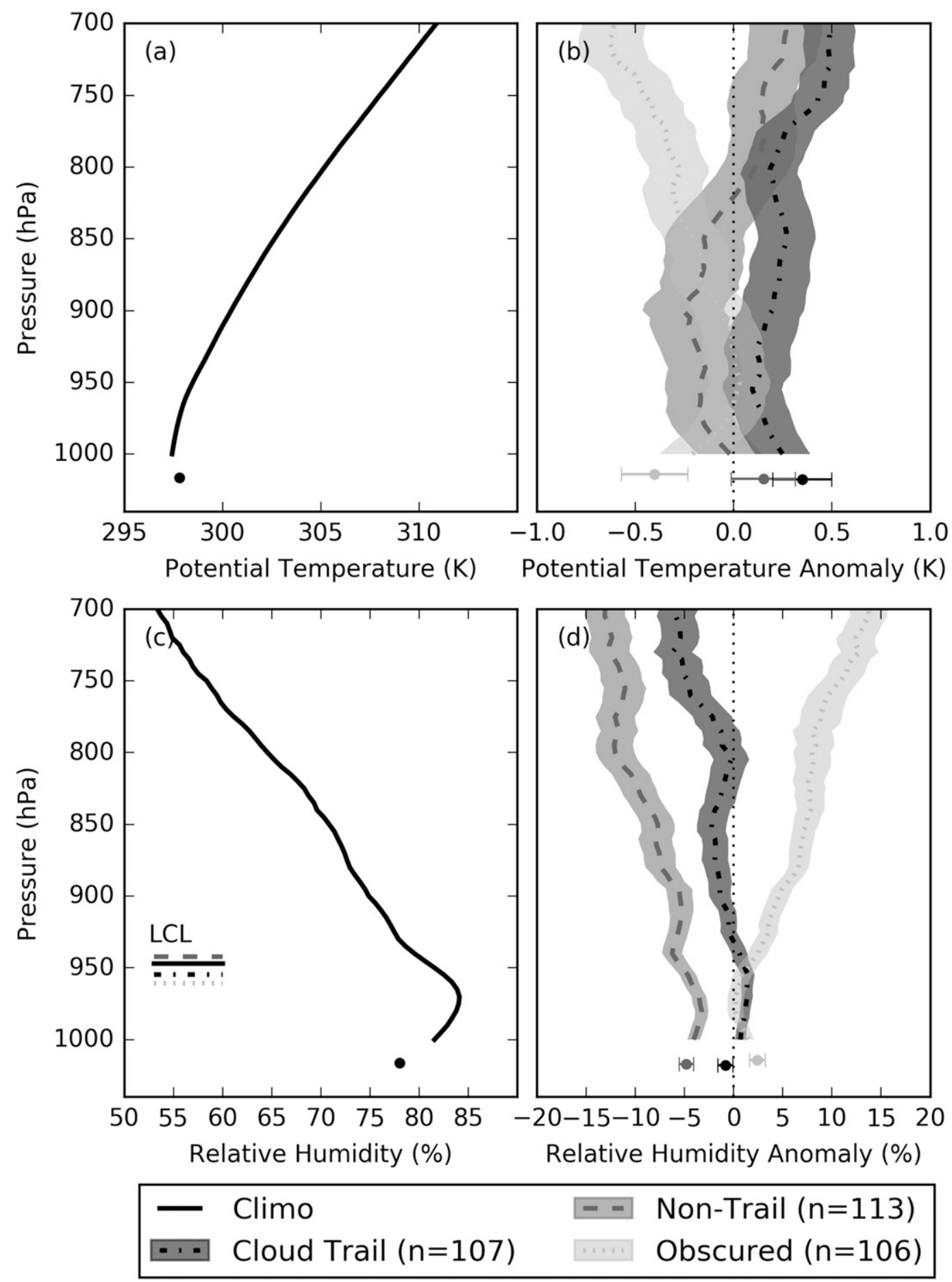

FIG. 4. (a) The climatological potential temperature $(\theta)$ profile. The mean surface $\theta$ is marked with a black dot. (b) The composite $\theta$ anomalies for CT (dash-dot line with dark gray shading), NT (dashed line with gray shading), and OB (dotted line with light gray shading). The shaded region represents the uncertainty about the mean anomaly: $\pm \sigma / \sqrt{N}$. The surface $\theta$ for each classification is shown by dots with the corresponding shade of gray. The range on the surface values is again $\pm \sigma / \sqrt{N}$. (c) The mean climatological relative humidity profile as in (a). The mean LCL for each classification and for the climatology are shown as horizontal line segments with corresponding line styles. (d) The composite relative humidity anomalies. Composites are for the $0900 \mathrm{LT}$ radiosondes for JJA in 2012-16. In each case, only data between the surface and $700 \mathrm{hPa}$ are shown. LCL pressures are calculated using the temperature and dewpoint of the lowest altitude reported by the radiosonde and Eqs. (5) and (6). 
both climatology $(949 \mathrm{hPa})$ and NT-dominated days $(941 \mathrm{hPa})$. Lower LCL heights suggest cloud formation is more readily achievable and these results provide a plausible explanation for why cloud trail formation is sensitive to low-level humidity.

In addition to thermodynamic profiles, wind speed is expected to influence the types of circulation that result from island surface heating by contributing to the organization of any cloud that forms. In dry idealized two- and three-dimensional simulations, Savijarvi and Matthews (2004), Kirshbaum (2013), and Kirshbaum and Wang (2014) show that for light or calm background wind regimes, thermally induced circulations form over a surface heat source (reminiscent of pure sea breezes). For stronger background winds, thermally induced circulations form a band of ascent downwind of the heat source (reminiscent of CT).

The mean wind speed for each classified scene is shown in Table 2 (top). The NT scenes are associated with lighter winds and $\mathrm{OB}$ scenes are associated with stronger winds than both $\mathrm{CT}$ scenes and all scenes. While lighter winds on NT days are possibly related to the turbulent generation of cloud over the island, or instances of cloud related to sea-breeze convergence rather than $\mathrm{CT}$ formation, stronger winds associated with $\mathrm{OB}$ scenes are likely related to large-scale disturbances.

Furthermore, Bermuda is oriented such that its long axis runs approximately southwest-northeast. From a Lagrangian perspective, surface heating is maximized for low-level flow parallel to the long axis of an island as an air parcel remains over the island heat source longer. For southwesterly and westerly winds, more non-OB scenes are classified as CT $(36 \%-39 \%)$ than NT $(23 \%-$ $28 \%$ ) [Table 2 (bottom)]. For all other wind directions, including northeasterly flow, which is also parallel to the long axis of the island, a greater proportion of non-OB scenes are classified as NT than CT.

Examining the larger-scale fields aids in explaining this result. We have already established that low-level moisture is a dominant control on cloud trail formation. ERA-Interim composites of the 0900 LT 1000-hPa specific humidity for JJA in Figs. 5a, 5c, and 5e show that Bermuda lies in a moisture gradient pointing from northeast to southwest for all classifications. Given this background moisture pattern, northeasterly flow results in advection of drier low-level air on average. Such a flow therefore tends to make the environment less favorable for $\mathrm{CT}$ on average despite maximizing low-level heating by maintaining a direction parallel to the long axis of the island.

Indeed, these composites are consistent with the radiosonde and surface composites in Fig. 4. They indicate that $\mathrm{CT}$ and $\mathrm{OB}$ days have similarly high low-level
TABLE 2. (top) Mean 10-m wind speed $\left(\mathrm{m} \mathrm{s}^{-1}\right.$ ) at Bermuda's L. F. Wade International Airport by algorithm classification. The number of observations in each classification is included in parentheses. (bottom) The percent of scenes in each classification and the total number of classified scenes by wind direction.

\begin{tabular}{|c|c|c|c|c|}
\hline & $\mathrm{CT}$ & NT & OB & All \\
\hline \multicolumn{5}{|c|}{ Mean wind speed } \\
\hline & $5.27(5191)$ & $4.83(5196)$ & $6.18(6013)$ & $5.46(16400)$ \\
\hline \multicolumn{5}{|c|}{ Wind direction } \\
\hline $\mathrm{N}$ & $27 \%$ & $44 \%$ & $29 \%$ & 1197 \\
\hline $\mathrm{NE}$ & $26 \%$ & $39 \%$ & $35 \%$ & 1318 \\
\hline $\mathrm{E}$ & $23 \%$ & $31 \%$ & $46 \%$ & 1578 \\
\hline SE & $27 \%$ & $32 \%$ & $41 \%$ & 2000 \\
\hline S & $33 \%$ & $33 \%$ & $34 \%$ & 2747 \\
\hline SW & $36 \%$ & $23 \%$ & $41 \%$ & 2861 \\
\hline $\mathrm{W}$ & $39 \%$ & $28 \%$ & $33 \%$ & 3399 \\
\hline NW & $29 \%$ & $40 \%$ & $31 \%$ & 1300 \\
\hline
\end{tabular}

specific humidity while NT days have lower specific humidity. Additionally, the western part of the BermudaAzores high (indicated by the $1020-\mathrm{hPa}$ contour) is shown to extend its control on this region for much of JJA, and it retreats to the east on OB days. This pressure pattern implies a wind field dominated by westerlies and southwesterlies at Bermuda with the lightest winds on NT days.

Finally, the composites show 500-hPa vertical motion between 0.00 and $0.01 \mathrm{~Pa} \mathrm{~s}^{-1}$ near Bermuda on CTdominated days (Fig. 5b), about $0.01 \mathrm{Pas}^{-1}$ on NTdominated days (Fig. 5d), and about $-0.11 \mathrm{~Pa} \mathrm{~s}^{-1}$ on OB-dominated days (Fig. 5f). Weak 500-hPa vertical motions or subsidence seen on CT- and NT-dominated days is consistent with the expected lack of large-scale cloudiness and favors shallow convection. This subsidence may also help to explain the drier and more stable than normal layer seen in the sounding composites for NT-dominated days.

\section{Conclusions}

This study presents an algorithm to automate the classification of conventional visible-channel satellite imagery into cloud trail, nontrail, and obscured categories at Bermuda. The algorithm first filters out morning and evening images with high solar zenith angles. It then masks cloudy pixels using a simple binary threshold method. Next, the algorithm determines whether a scene is obscured by cloud by considering the cloud fraction within $0.25^{\circ}$ of the island. For nonobscured scenes, the observed $10-\mathrm{m}$ wind direction at the time of the satellite image is then used to define an upwind and downwind region with respect to the island. A scene is then determined to include a cloud trail by 

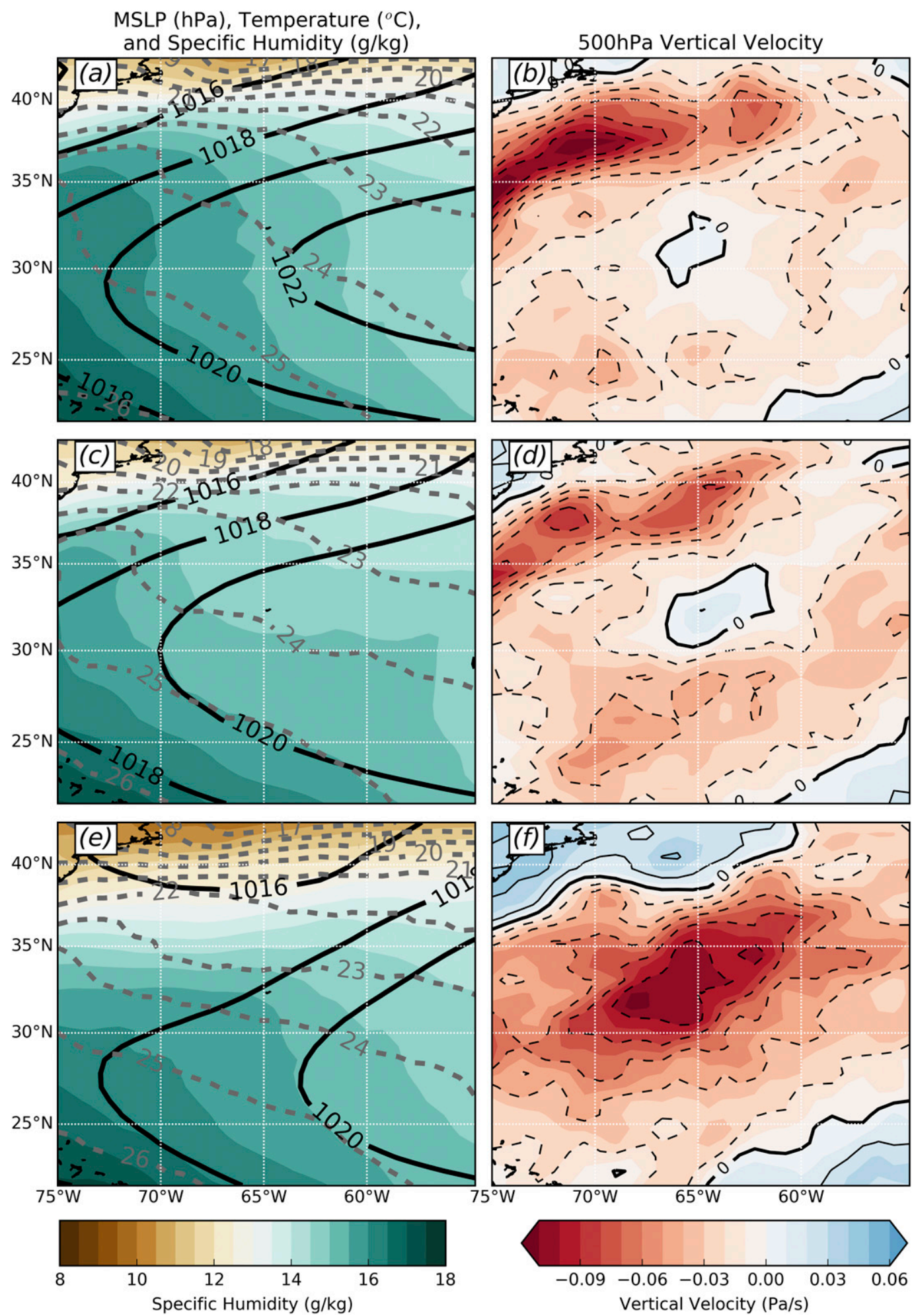

FIG. 5. JJA 2012-16 ERA-Interim reanalysis composites centered on Bermuda. Composites for (a),(b) cloud trails; (c),(d) nontrails; and (e),(f) obscured. (left) The mean sea level pressure in hPa (solid black contours), 1000-hPa temperature in ${ }^{\circ} \mathrm{C}$ (dashed gray contours), and 1000-hPa specific humidity in $\mathrm{g} \mathrm{kg}^{-1}$ (shading). (right) The 500-hPa vertical velocity in $\mathrm{Pa} \mathrm{s}^{-1}$, ascent (red) and subsidence (blue) are shown in dashed and solid contours, respectively. 
considering the difference between downwind and upwind cloud fractions. The resulting classification is found to be consistent with a manual classification of a subset of the data from May to October 2012.

The resulting classifications for the May-October 2012-16 period from this algorithm show both an annual and diurnal cycle in cloud trail occurrence at Bermuda. The CT occurrence is found to peak in July and between 1300 and 1500 LT. Between May and July CT occurrence increases while OB occurrence decreases. This corresponds to the period in which the Bermuda-Azores high enforces increasingly settled weather across Bermuda into July. From July to October, the fraction of $\mathrm{OB}$ scenes increases and the fraction of $\mathrm{CT}$ scenes decreases.

Similarly, CT occurrence increases during the day while the fraction of NT classifications decreases. This is likely in response to the stronger solar heating present in the afternoon, and therefore stronger thermal forcing for the development of CT on otherwise non-OB days.

These classifications are then used to explore the characteristics of the environments present in the morning of days in JJA on days predominately in each classification. Radiosonde composites show that CTdominated days are characterized by conditions that are near the mean potential temperature and relative humidity for the JJA period in 2012-2016. Surface observations and ERA-Interim data show that lower than normal low-level potential temperature and relative humidity, lighter than normal $10-\mathrm{m}$ winds, and $500-\mathrm{hPa}$ subsidence are associated with NT-dominated days. Lower than normal low-level potential temperature, higher than normal low-level relative humidity, stronger than normal $10-\mathrm{m}$ winds, and $500-\mathrm{hPa}$ ascent are associated with OB-dominated days.

Differences in low-level humidity appear to be the most important factor in determining whether or not a non-OB day will have a CT. Days with higher low-level humidity result in lower LCL and therefore the level to which turbulent mixing must reach in order for condensation and cloud formation is lower. Also of importance is the role of the low-level wind speed and direction, which controls the low-level heating following air across the island. Wind speed controls whether or not the buoyant production of turbulence and the induced circulation is confined to the island in light wind regimes, or whether thermally generated circulations are formed downwind of the island in regimes with some background wind. Particularly for noncircular islands, wind speed and direction control the residence time of air as it crosses the heated island and therefore the strength of the thermally induced circulation.
Some additional insight into the behavior of cloud trails through the day is gained. We find that more than one cloud trail can form per day, each lasting a few hours. Other times, a single continuous cloud trail is observed. In an environment that is only marginally conducive for cloud trail formation, this transient behavior might be explained by subtle changes in wind direction, low-level humidity, or large-scale vertical motion through the day that periodically cut off activity before allowing it to resume later in the day.

Composites based on days predominantly in each classification, and theory from past literature, suggest that nonobscured days are likely to have cloud trails given the following:

1) Sufficient low-level humidity and therefore relatively low LCL to support cloud formation.

2) Maximized low-level heating from a Lagrangian perspective. This is achieved via long-axis parallel low-level flow and low solar zenith angles.

3) Sufficiently strong low-level flow such that a pure sea-breeze circulation is not favored over a steady heat island circulation.

This study takes a step closer to fully characterizing the environments that are conducive for CT formation, however, it presents further questions about their behavior. A future study might be able to use multispectral satellite imagery to extend this analysis through the nighttime hours and this could further our understanding of what happens to cloud trails after sunset. For instance, imagery from the newly operational GOES-16 satellite includes a 3.9- $\mu \mathrm{m}$ channel at $2-\mathrm{km}$ resolution that might be appropriate for this purpose (Schmit et al. 2017).

As operational numerical weather prediction systems are approaching the ability to resolve phenomena on these scales, it is increasingly important to present a complete characterization of their behavior. For instance, thermally driven circulations may still be present downwind of islands in NT cases and incorrectly simulating the strength of this circulation might result in cloud formation where it should not exist. Therefore, future investigation is required to fully understand the initiation, persistence/ transience, and any potential transition from a shallow to deep convective state. However, conventional observations like those presented are likely insufficient to describe these characteristics, and high-resolution idealized simulations are therefore planned.

Acknowledgments. Surface station data for Bermuda were provided on behalf of the government of Bermuda Department of Airport Operations by the Bermuda Weather Service operated by $\mathrm{CI}^{2}$ Aviation, formerly BAS-Serco Ltd. Raw satellite data were 
downloaded from NOAA's Comprehensive Large Array-Data Stewardship System (CLASS) and radiosonde data were obtained from NCDC's Integrated Global Radiosonde Archive, version 2 (IGRAv2).

\section{APPENDIX}

\section{Additional Algorithm Assessment}

\section{a. Choice of algorithm parameters}

The choice of $\alpha$ and $\beta$ as described in section $2 \mathrm{~d}$ is expanded upon here. Figure A1 shows the cumulative distribution functions for the cloud fraction for scenes that were manually classified as $\mathrm{OB}$, and the inverse cumulative distribution function for the cloud fraction for scenes that were manually classified as either NT or CT (i.e., non-OB). Similarly, Fig. A2 shows the cumulative distribution function for the difference between the sector with maximum cloud fraction in the downwind quadrant and the sector with the maximum cloud fraction in the upwind quadrant for scenes that were manually classified as CT, and the inverse cumulative distribution function for scenes that were manually classified as NT.

In Figs. A1 and A2, the point of intersection is taken to be the optimal value for distinguishing between the two classifications-either OB or non-OB in the case of $\alpha$, and either CT or NT in the case of $\beta$. This maximizes the Peirce skill score and yields $\alpha=0.33$ and $\beta=0.08$.

\section{b. Algorithm versus manual classification for 2012 warm season}

In addition to the verification metrics presented in the text, and the contingency table in Table 1, we also reproduce part of the analysis on the manually classified data from May to October 2012, and compare that to the analysis performed on the algorithm classifications for the same period.

Figure A3 shows the variation of the percentage of classifications with time of day and month of year. It is found that there is generally good agreement between the manual and algorithm classifications; however, the biggest differences are between the CT and NT classifications in Figs. A3a and A3b. In the algorithm, there are too many morning CT classifications and too few morning NT classifications when compared to the manual classification. This is particularly the case in the July-October timeframe. However, the algorithm reproduces both the annual and diurnal cycles reasonably well, although the amplitude of the diurnal cycle is somewhat lower in algorithm classifications compared

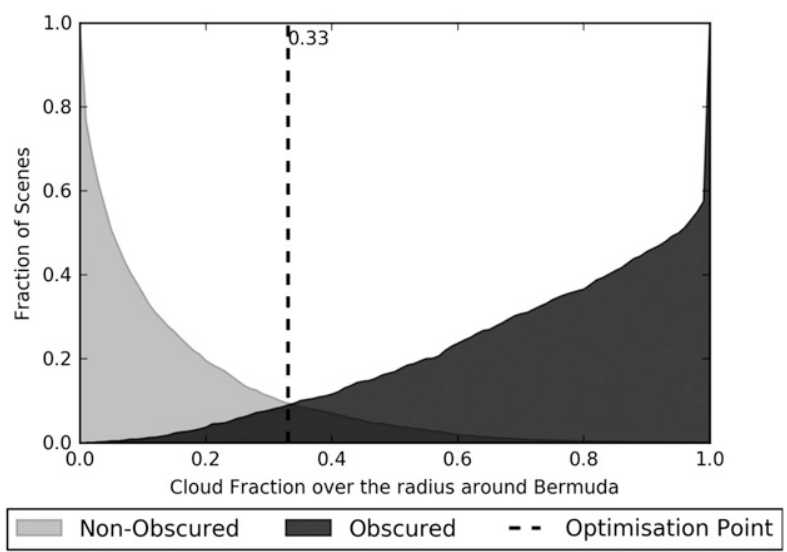

FIG. A1. Cumulative distribution function of the cloud fraction for OB scenes and the inverse cumulative distribution function of the cloud fraction for non-OB scenes. The cloud fraction value at the intersection of these two distributions, 0.33 , is taken as the value of our parameter $\alpha$.

to the manual classification because there are more morning algorithm CT.

Similarly, the frequency of each classification by month also shows a high level of agreement (Fig. A4). A total of 51 more scenes were classified as CT by the algorithm than manually, 231 fewer scenes were classified as NT by the algorithm, and 82 more scenes were classified as OB. As a percentage of the corresponding manual classifications, this amounts to $5 \%$ more CT scenes in the algorithm, $18 \%$ fewer NT scenes in the algorithm, and $7 \%$ more OB scenes in the algorithm. Qualitative characteristics (e.g., the timing of peak occurrence) of the annual cycle are largely preserved by the algorithm.

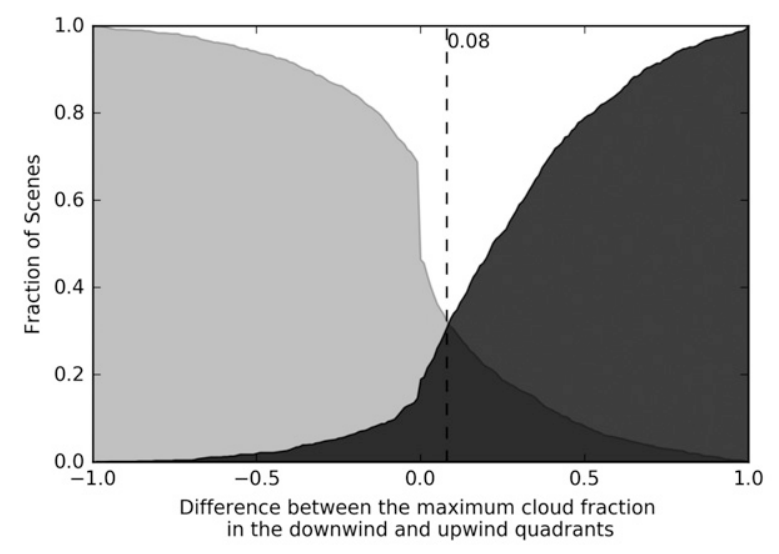

Non-Trail Cloud Trail - - Optimisation Point

FIG. A2. Cumulative distribution function of the difference in maximum downwind and upwind cloud fraction $\delta F$ for CT scenes compared to $\delta F$ for NT scenes. The difference at the intersection of these two distributions, 0.08 , is taken as the value of our parameter $\beta$. 


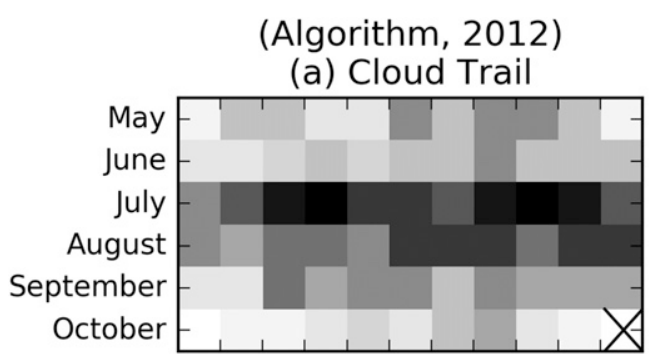

(b) Non-Trail

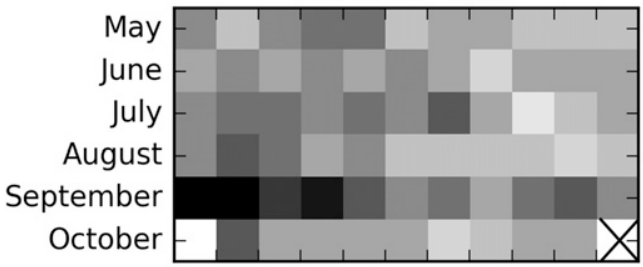

(c) Obscured

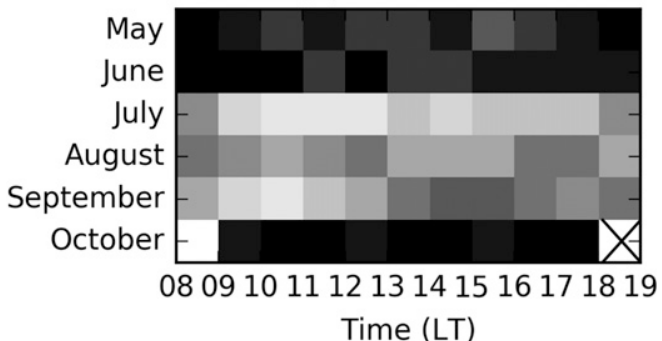

(Manual, 2012)

(d) Cloud Trail

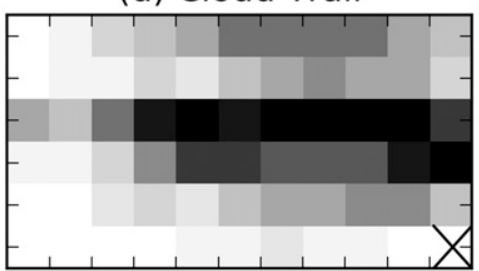

(e) Non-Trail

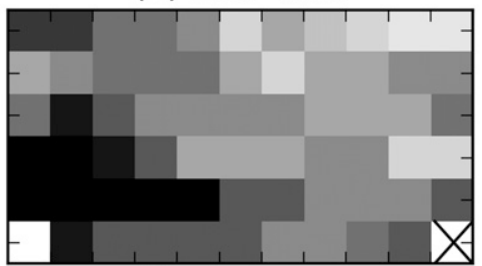

(f) Obscured

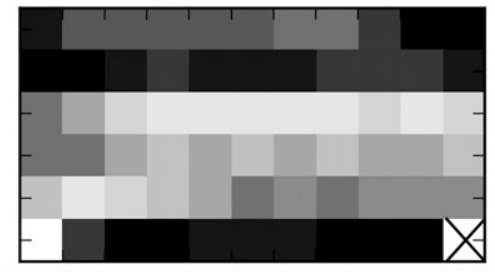

080910111213141516171819

Time (LT)

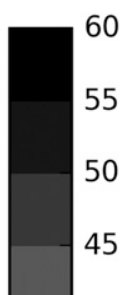

FIG. A3. As in Fig. 3, but for the classifications from May to October 2012. (a)-(c) Algorithm classifications are compared with (d)-(f) the manual classifications.

Finally, Fig. A5 shows the composite profiles on CT, NT, and OB days in JJA 2012. We show that, again, the algorithm classification is able to adequately reproduce the results from the manual classification. The composite sounding anomalies from the analysis performed using the algorithm classifications is within the uncertainty ranges of the analysis performed using the manual classifications for both the relative humidity and potential
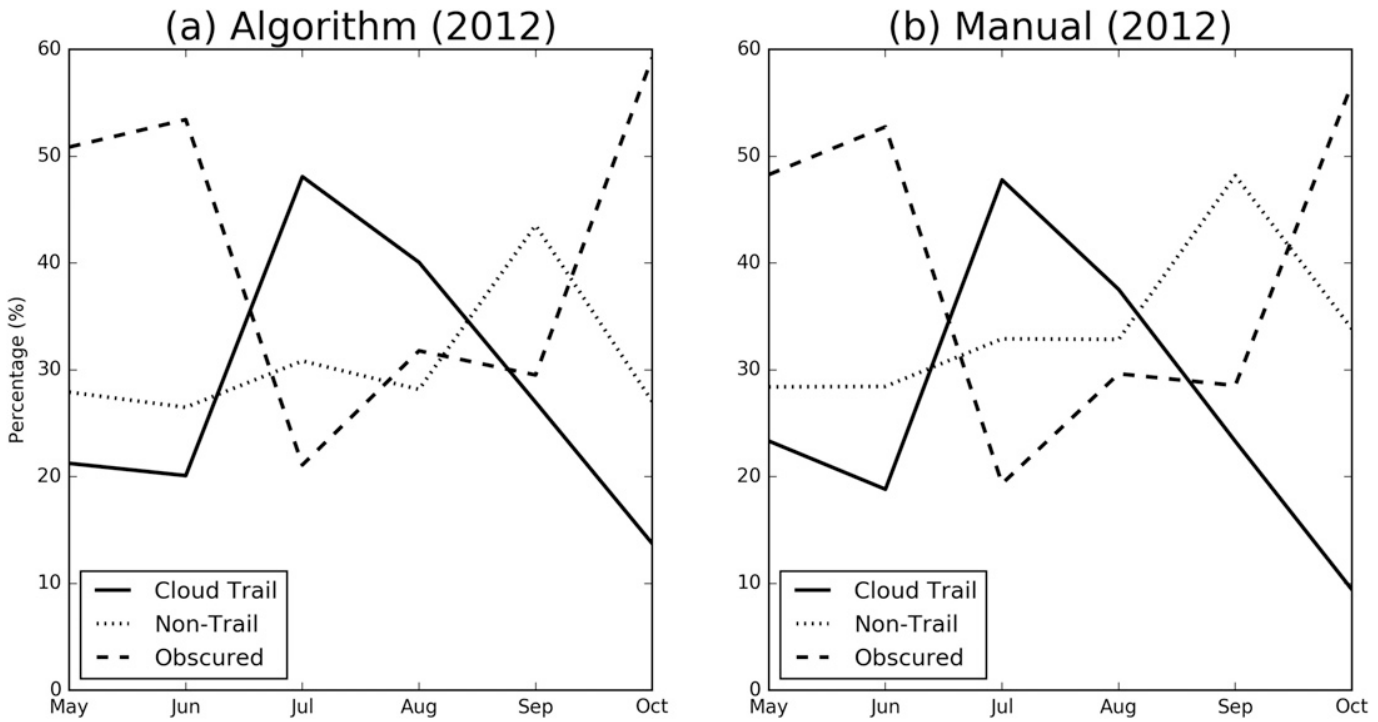

FIG. A4. The percentage of all scenes in each month from May to October 2012 that are classified as cloud trail (solid line), nontrail (dotted line), and obscured (dashed line). This analysis is done for (a) the algorithm classification and (b) the manual classifications. 

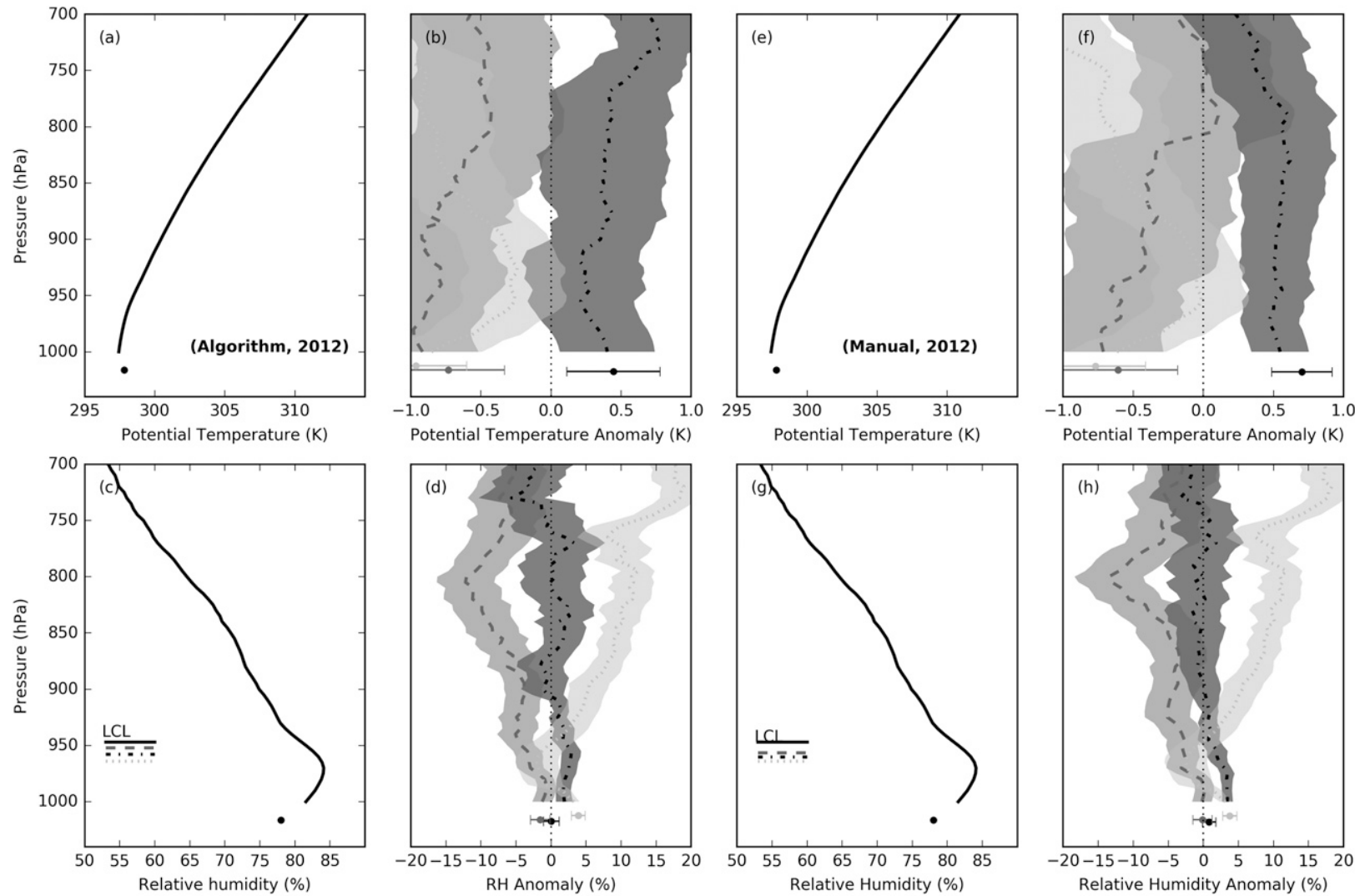

Potential Temperature Anomaly (K)

$\begin{array}{|lll|}- & \text { Climo } & \text { Non-Trail }(n=27) \\ \cdots & \text { Cloud Trail }(n=22) & \text { Obscured }(n=22)\end{array}$

\begin{tabular}{lll|}
- & Climo & Non-Trail $(n=23)$ \\
$\cdots$ & Cloud Trail $(n=23)$ & Obscured $(n=22)$
\end{tabular}

FIG. A5. As in Fig. 4, but for the classifications from May to October 2012. Note that these are anomalies with respect to the 2012-16 JJA climatology. For comparison, these profiles are made for (a)-(d) the algorithm classifications and (e)-(h) the manual classifications.

temperature anomalies. The two classification methods are consistent in terms of the relationship between classifications and the LCL-obscured days have the lowest LCL, followed by CT, and then NT days with the highest LCL.

\section{REFERENCES}

Bhumralkar, C. M., 1973: An observational and theoretical study of atmospheric flow over a heated island: Part I. Mon. Wea. Rev., 101, 719-730, https://doi.org/10.1175/1520-0493(1973)101<0719: AOATSO $>2.3 . \mathrm{CO} ; 2$.

Bolton, D., 1980: The computation of equivalent potential temperature. Mon. Wea. Rev., 108, 1046-1053, https://doi.org/ 10.1175/1520-0493(1980)108<1046:TCOEPT $>2.0$. CO;2.

CIA, 2017: The CIA World Factbook: Bermuda. CIA, accessed 18 May 2017, https://www.cia.gov/library/publications/the-worldfactbook/geos/bd.html.

Crook, N. A., 2001: Understanding Hector: The dynamics of island thunderstorms. Mon. Wea. Rev., 129, 1550-1563, https://doi.org/ 10.1175/1520-0493(2001)129<1550:UHTDOI > 2.0.CO;2.

, and D. F. Tucker, 2005: Flow over heated terrain. Part I: Linear theory and idealized numerical simulations. Mon. Wea. Rev., 133, 2552-2564, https://doi.org/10.1175/MWR2964.1.
Davis, R. E., B. P. Hayden, D. A. Gay, W. L. Phillips, and G. V. Jones, 1997: The North Atlantic subtropical anticyclone. J. Climate, 10, 728-744, https://doi.org/10.1175/1520-0442 (1997) $010<0728:$ TNASA $>2.0$. CO;2.

Dee, D. P., and Coauthors, 2011: The ERA-Interim reanalysis: Configuration and performance of the data assimilation system. Quart. J. Roy. Meteor. Soc., 137, 553-597, https://doi.org/ 10.1002/qj.828.

Dorman, C. E., 1994: Guadalupe Island cloud trail. Mon. Wea. Rev., 122, 235-242, https://doi.org/10.1175/1520-0493(1994)122<0235: GICT $>2.0 . \mathrm{CO} ; 2$

Durre, I., R. S. Vose, and D. B. Wuertz, 2006: Overview of the integrated global radiosonde archive. J. Climate, 19, 53-68, https://doi.org/10.1175/JCLI3594.1.

,$- \ldots$, and -2008 : Robust automated quality assurance of radiosonde temperatures. J. Appl. Meteor. Climatol., 47, 20812095, https://doi.org/10.1175/2008JAMC1809.1.

Estoque, M. A., and C. M. Bhumralkar, 1969: Flow over a localized heat source. Mon. Wea. Rev., 97, 850-859, https://doi.org/10.1175/1520-0493(1969)097<0850:FOALHS> 2.3.CO;2.

Garstang, M., P. D. Tyson, and G. D. Emmitt, 1975: The structure of heat islands. Rev. Geophys., 13, 139-165, https://doi.org/ 10.1029/RG013i001p00139. 
Kirshbaum, D. J., 2013: On thermally forced circulations over heated terrain. J. Atmos. Sci., 70, 1690-1709, https://doi.org/ 10.1175/JAS-D-12-0199.1.

— , and C.-C. Wang, 2014: Boundary layer updrafts driven by airflow over heated terrain. J. Atmos. Sci., 71, 1425-1442, https://doi.org/10.1175/JAS-D-13-0287.1.

_ , and J. G. Fairman, 2015: Cloud trails past the Lesser Antilles. Mon. Wea. Rev., 143, 995-1017, https://doi.org/10.1175/MWR-D14-00254.1.

Malkus, J. S., 1952: Recent advances in the study of convective clouds and their interaction with the environment. Tellus, $\mathbf{4}$, 71-87, https://doi.org/10.3402/tellusa.v4i2.8680.

__ 1963: Tropical rain induced by a small natural heat source. J. Appl. Meteor., 2, 547-556, https://doi.org/10.1175/15200450(1963)002<0547:TRIBAS > 2.0.CO;2.

— over Nantucket Island during the summer of 1950. Pap. Phys. Oceanogr. Meteor., 12,1-50.

- , and M. E. Stern, 1953: The flow of a stable atmosphere over a heated island, Part I. J. Meteor., 10, 30-41, https://doi.org/ 10.1175/1520-0469(1953)010<0030:TFOASA > 2.0.CO;2.

Matthews, S., J. M. Hacker, J. Cole, J. Hare, C. N. Long, and R. M. Reynolds, 2007: Modification of the atmospheric boundary layer by a small island: Observations from Nauru. Mon. Wea. Rev., 135, 891-905, https://doi.org/10.1175/MWR3319.1.

McFarlane, S. A., C. N. Long, and D. M. Flynn, 2005: Impact of island-induced clouds on surface measurements: Analysis of the ARM Nauru Island effect study data. J. Appl. Meteor., 44, 1045-1065, https://doi.org/10.1175/JAM2241.1.

NOAA/Office of Satellite and Product Operations and NOAA/ Center for Satellite Applications and Research, 1994: NOAA GOES 8-15 Series Imager Level 1b Data. Channel 1, NOAA National Centers for Environmental Information, accessed 24 February 2017.

Nordeen, M. K., P. Minnis, D. R. Doelling, D. Pethick, and L. Nguyen, 2001: Satellite observations of cloud plumes generated by Nauru. Geophys. Res. Lett., 28, 631-634, https://doi.org/ 10.1029/2000GL012409.

Peirce, C. S., 1884: The numerical measure of the success of predictions. Science, 4, 453-454, https://doi.org/10.1126/science.ns-4.93.453-a.
Robinson, F. J., S. C. Sherwood, D. Gerstle, C. Liu, and D. J. Kirshbaum, 2011: Exploring the land-ocean contrast in convective vigor using islands. J. Atmos. Sci., 68, 602-618, https:// doi.org/10.1175/2010JAS3558.1.

Savijarvi, H., and S. Matthews, 2004: Flow over small heat islands: A numerical sensitivity study. J. Atmos. Sci., 61, 859-868, https://doi.org/10.1175/1520-0469(2004)061<0859: FOSHIA $>2.0 . \mathrm{CO} ; 2$

Schmit, T. J., P. Griffith, M. M. Gunshor, J. M. Daniels, S. J. Goodman, and W. J. Lebair, 2017: A closer look at the ABI on the GOES-R series. Bull. Amer. Meteor. Soc., 98, 681-698, https://doi.org/10.1175/BAMS-D-15-00230.1.

Smith, R. B., A. C. Gleason, P. A. Gluhosky, and V. Grubisić, 1997: The wake of St. Vincent. J. Atmos. Sci., 54, 606-623, https://doi.org/10.1175/1520-0469(1997)054<0606:TWOSV> 2.0.CO;2

Smolarkiewicz, P. K., R. M. Rasmussen, and T. L. Clark, 1988: On the dynamics of Hawaiian Cloud bands: Island forcing. J. Atmos. Sci., 45, 1872-1905, https://doi.org/10.1175/15200469(1988)045<1872:OTDOHC $>2.0$. CO 2 .

Sobel, A. H., C. D. Burleyson, and S. E. Yuter, 2011: Rain on small tropical islands. J. Geophys. Res., 116, D08102, https://doi.org/ 10.1029/2010JD014695

Williams, E., T. Chan, and D. Boccippio, 2004: Islands as miniature continents: Another look at the land-ocean lightning contrast. J. Geophys. Res., 109, D16206, https://doi.org/10.1029/ 2003JD003833.

Yang, Y., and Y.-L. Chen, 2008: Effects of terrain heights and sizes on island-scale circulations and rainfall for the Island of Hawaii during HaRP. Mon. Wea. Rev., 136, 120-146, https://doi.org/ 10.1175/2007MWR1984.1.

_ - S.-P. Xie, and J. Hafner, 2008a: The thermal wake of Kauai Island: Satellite observations and numerical simulations. J. Climate, 21, 4568-4586, https://doi.org/10.1175/ 2008JCLI1895.1.

$\left[, \ldots\right.$, and $\_, 2008$ b: Cloud patterns lee of Hawaii Island: A synthesis of satellite observations and numerical simulation. J. Geophys. Res., 113, D15126, https://doi.org/10.1029/ 2008JD009889. 